\title{
IUD Contraceptive Use Among Women of Reproductive Age: Experiences, Motivators and barriers in a General Hospital, Uganda
}

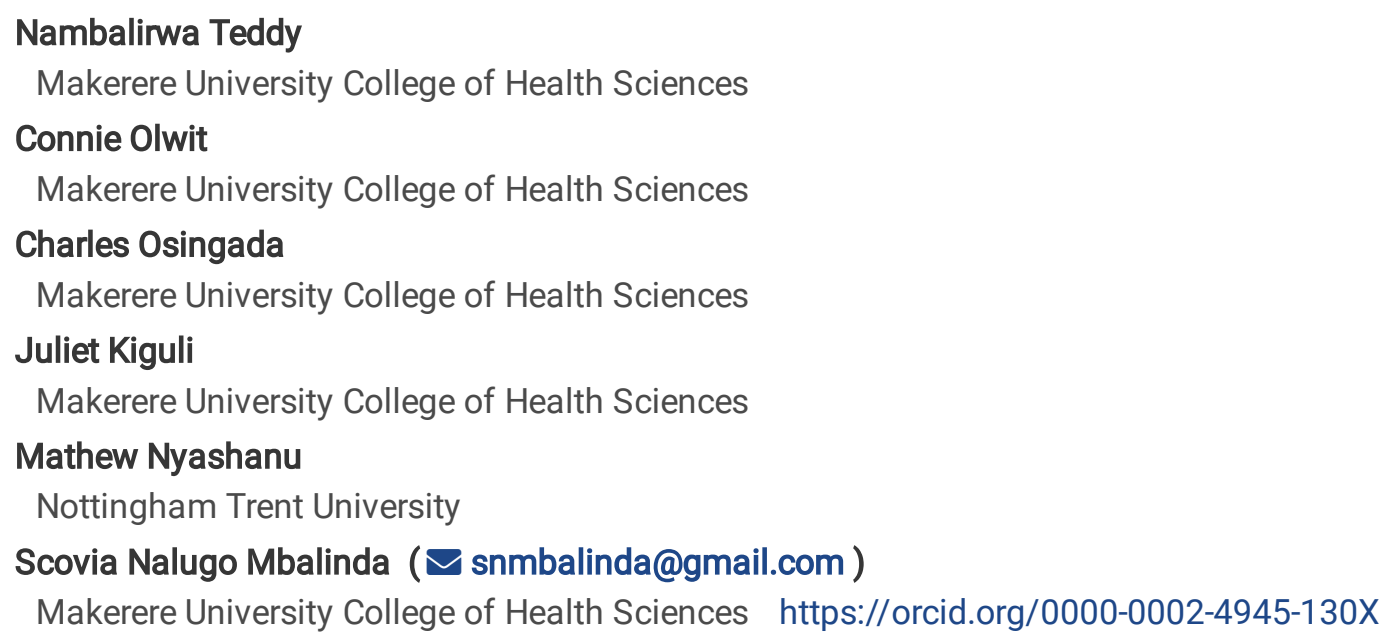

Research

Keywords: IUD, Family planning

Posted Date: May 28th, 2020

DOI: https://doi.org/10.21203/rs.3.rs-29639/v1

License: (a) (i) This work is licensed under a Creative Commons Attribution 4.0 International License. Read Full License 


\section{Abstract}

\section{Background}

Despite availing contraceptives, IUD uptake remains low in family planning service provision. Yet there is evidence that access to family planning reduces Maternal mortality especially in developing countries like Uganda. The study explored the reasons for low uptake of IUD among women of reproductive age.

Methodology

Focus-groups and in-depth interviews with women in reproductive was employed to explore experiences, barriers and for low use of IUD. A thematic analysis was used to analyse the data.

Results

This study explored women's experiences, their motivations and barriers to IUD use. The positive experiences reported included; IUD is a long-term method of family planning; un affected libido, body image, reassurance from the health providers. The negative experiences included; pain on insertion; discomfort and bleeding and fear of strings. The motivators were; availability of IUD services at the facility, unaffected body image, information from the health workers and the barriers included; mistrust of health providers, financial constraints, myth and misconceptions and lack of social support.

\section{Conclusion}

The experiences were both positive and negative, the motivators were their drivers to use the method and barriers were reported to influence the IUD use. There is need for mothers who have used IUD and are satisfied with the method to talk to other mothers so that we can increase IUD use as a method of family planning and health care providers have role to play to demystify the myth and misconceptions the mother have.

\section{Background}

Globally, one of the major causes of maternal mortality is abortion which is estimated to be at 7.9\% (1). Lack of family planning leads to unintended pregnancies which in turn result into unsafe abortions (2). Family planning reduces women's health risks as a result of abortion, hemorrhage, uterine perforation, cervical injury, medical complications which lead to death and infections due to incomplete abortion. This helps in reduction of maternal morbidity, mortality and slows population growth. However, only $14.3 \%$ of women of reproductive age are using intra uterine contraceptive worldwide. In Africa, Intra Uterine Device (IUD) use is even lower where only $4 \%$ of women of reproductive age use it (3).

Much as efforts is put through different programs about Long Acting Reversible Contraceptive (LARC) family planning methods to increase their uptake, in Uganda IUD use is still low. IUD use was at $0.2 \%$ in 2006 , slightly increased to $0.4 \%$ in 2011 , and there is a gradual increase from $0.6 \%$ in 2014 to $1.1 \%$ in 2016 (4). Although there is a slight increase, IUD use is still very low despite its effectiveness, long lasting and need no mother's adherence. And this has reduced on the numbers of maternal morbidity and mortality rate through avoiding un intended pregnancy (Rowe, Farley, Peregoudov, Piaggio, \& Boccard, 2016). A study done by Twesigye (5)showed most women reported negative attitudes, misconceptions and misinformation about IUD as compared to positive attitudes. Therefore, in this qualitative study there was need to understand why there is low uptake of IUD contraceptives by listening to women experiences while using IUDs and exploring what prevents others from using them.

The fertility rate in Uganda of 5.71 children born per woman and maternal mortality rate of 343 deaths per 10000 live birth is also high (4). The high mortality rate could be due to the unwanted pregnancies, short birth intervals and a high risk of obstetric complications associated with low contraceptive use (6). Uganda demographic and health survey showed high level of unintended pregnancies (44\%) with unsafe abortion estimated to be 62 per 1000 women of age between 15-49 years which accounts for $26 \%$ of maternal deaths in Uganda. Other districts in the country such as Nakaseke through Ministry of Health $(\mathrm{MOH})$ has availed efforts scaling up family planning in reaction to unwanted pregnancies. Different strategies have been 
established in the public sector as interventions through training provider per selected facility. In addition, one reproductive health focal person per district in IUD service delivery and use of community extension workers have also been recognized to help those not accessing the IUD services due to economic, social and geographical areas.

Despite the comprehensive efforts by $\mathrm{MOH}$ to increase IUD uptake, it has continued to be very low $1.1 \%$ with about $10 \%$ of early discontinuation in the first 90 days of insertion (4). With this health system effort in perspective, there is need to understand barriers, motivations and explore experiences of users of IUD.

\section{Methodology}

\section{Study design}

A qualitative study using focus-group and in-depth interviews with women in reproductive was employed to explore experiences, barriers and motivators for use of IUD as a family planning method.

\section{Study population}

The study included Women of Reproductive Age (WRA) that is 15-49 years at family planning clinic in general hospital.

\section{Study Site}

The study was conducted in Nakaseke Hospital located in Nakaseke district. Nakaseke hospital serves several neighboring districts of Luweero, Wakiso, Nakasongola, and Mityana. The family planning clinic operates from Monday to Friday and receives approximately 40 mothers per day.

\section{Data Collection}

Purposive sampling was used to recruit women who had come for IUD family planning method and those who had come for any family planning method. This sampling method enabled researchers to recruit participants with a wide range of age who were grouped according to their age to facilitate free expression during the Focus Group Discussions (FGDs). Four (4) FGDs with 10 participants per group were conducted and eight (8) in depth interviews were conducted to further explore what had been raised in the FGDs.

Research participants were aged (15-49) and were using any of the family planning method at the family planning clinic and were able to speak English or Luganda fluently.

An in-depth interview guide was developed in English and translated into Luganda. The interview guide consisted of questions about experiences of using IUD as a family planning method, and motivations. The interview guides were pretested before use to ensure that the questions were clear to the research participant's questions were clear for the women to understand and adjustments to the guides were made. The interviews were held at a family planning Centre in a private room. The researchers wrote to the managers of the family planning Centre inviting the women to take part in the study and only those who indicated willingness to take part in the study had their names passed on to the researchers. All research participants were given an information sheet and had the opportunity to ask questions. They also signed a consent form which allowed them to withdraw from the study without giving any reason. The interviews were audio recorded and transcribed verbatim for analysis.

\section{Data analysis}

The transcribed text was then translated from Luganda into English. A thematic analysis approach supported by captions from the interview was chosen, (7) The interviews were read through several times by all authors and the different statements were 
grouped, resulting in the construction of a map, in accordance with the description by Braun and Clark (7). Different themes and sub themes were identified and discussed and rearranged until a final pattern was distinguished.

\section{Ethical approval}

Makerere University, School of health Science Ethics committee \#SHSREC REF NO: 2018-065 and Nakaseke regional hospital granted ethical approval for this study.

\section{Results}

\section{Introduction}

The findings are from eight (8) in depth interviews of women who shared their experiences using IUDs and their motivations towards IUD contraceptive use. Four (4) FGD were carried out in this study with women using other contraceptive methods but not IUD to find out their experiences and barriers to IUD use. The findings in both data sources were triangulated and presented below.

\section{Description of the study participants.}

A total of eight participants were interviewed with WRA using IUD with age between 24-40 years and all were married apart from one who was a sex worker. Three of them attained a secondary level of education, three stopped in primary level and two reached tertiary level. All participants were Christians and all of them except one (1) were in working class, had at least one child. The rest of the characteristics were as shown in table1 below.

Table 1

A summary of socio-demographic characteristics of the IUD users

\begin{tabular}{|lllllll|}
\hline Participant number & Age & Marital status & Occupation & Religion & Level of education & No of children \\
\hline 1 & 29 & Married & Health worker & Protestant & Diploma & 2 \\
\hline 2 & 24 & Married & Not working & Protestant & S.4 & 1 \\
\hline 3 & 39 & Not married & Sex worker & Catholic & P5 & 2 \\
\hline 5 & 39 & Married & Business woman & Catholic & P7 & 6 \\
\hline 6 & 32 & Married & Business woman & Born again & S.4 & 2 \\
\hline 7 & 30 & Married & Health worker & Catholic & Diploma & 3 \\
\hline 8 & 29 & Married & Hair dresser & Catholic & S.4 & 3 \\
\hline
\end{tabular}


Table 2

Socio-demographic characteristics of women using other contraceptive methods but not IUD.

\begin{tabular}{|llll|}
\hline Variables & Category & Frequency & Percentage (\%) \\
\hline Age & $15-25$ & 20 & 63 \\
\cline { 2 - 4 } & $26-35$ & 10 & 31 \\
\hline \multirow{2}{*}{ Region of residence } & Central region & 32 & 100 \\
\hline Occupation & Working & 25 & 78 \\
\cline { 2 - 4 } Marital status & Not working & 7 & 22 \\
\hline \multirow{3}{*}{ Religion } & Married & 25 & 78 \\
\cline { 2 - 4 } & Not married & 7 & 22 \\
\hline \multirow{2}{*}{ Level of education } & Christians & 23 & 72 \\
& Moslems & 9 & 28 \\
\cline { 2 - 4 } & Secondary Level & 14 & 44 \\
\cline { 2 - 4 } & Not educated & 3 & 9 \\
\cline { 2 - 4 } & & 15 & 47 \\
\hline
\end{tabular}

\section{Experiences of using IUD contraceptive}

Experiences for mothers were assessed and both positive and negative experiences were reported. The positive experiences which were reported by women included; IUD is a long-term method of family planning; unaffected libido, convenient and comfortable for them. This was emphasized by a mother.

"That for it you insert it for a period you want as long as the person who has inserted it inserts it well, it can be there for that period until when you reach time when you are tired of it! More so you remain with your sexual feelings" (participant 1)

Women also reported that the method was convenient and comfortable for them, it does not need adherence like other methods and the side effects of other methods like injecta plan (depovera) where the experience was uncomfortable.

"Pills were giving me nausea and for the case of injector plan I would always be bleeding abnormally but for it (IUD) my menstrual days stay normal as there is nothing like missing my periods" (participant 4)

Some women reported that they were first screened for cervical cancer before the procedure and this created awareness of their status which they believed was good for their health.

"... of course, they first screened me for cervical cancer ...... and they confirmed that I was ok they inserted it" (participant 1)

Most women received support from health workers. Some health providers they re-assured them when they had concerns while using IUD by providing them with knowledge, their personal experiences for those who had used IUD, sensitizing and counseling them.

"The health worker who worked on me also had IUD for the last 5 years so she told me; I shouldn't worry that happened because of heavy bleeding. She also told me that if I happen to see again heavy bleeding, I should take Ibuprofen to reduce on the blood, that also candida disrupts IUD, so she emphasized the importance of personal hygiene, and that if I get it I should make sure I take medicine to avoid infections because its problem is infection" (participant 8) 
The negative experiences which were reported by women included pain on insertion, discomfort and bleeding after insertion.

"By the way nurse it can also cause prolonged menstrual bleeding like for two (2) additional days. I experienced prolonged bleeding for the first three (3) weeks when I had just started using it but it finally normalized "(participant5)

\section{Motivations to choose IUD contraceptive}

Women in this study cited several factors that motivated them to use IUDs. These included previous experience of failure from other contraceptives methods, availability of the IUD services at the facility, unaffected body image while using IUDs and information from the health providers, peer influence and media.

Failure of the other family planning method motivated some clients to use IUD.

", the condom burst, then I got pregnant and before that pregnant, I had undergone a C-section (for that last born), they don't allow you to give birth to another child when the child is not yet 3 years, by then he was like one month so I got pills from the hospital and aborted. IUD." (participant 37)

Peer influence and relying on the information provided by the health providers motivated some mothers to use IUD.

"what also motivated me was that it has no problem in the body the way health providers teach us, right now I also feel free as if I don't have anything in my body, there is nothing like pulsations, (participant 8)

Side effects of other family planning methods such as irregular bleeding, change in body size, motivated the women to use IUD "for 1st born I was using injectaplan and I could not manage it then I stopped... I was not menstruating... ok it also used to make me have a headache... for the 2nd born I used implant... even with it I was not menstruating, and it used to bring headache and pulsations" (Participant 7)

\section{Barriers influencing the nonuse of IUD contraceptive}

The decision to use or not to use FP services is the product of several demographic and service-related barriers. In this study the following themes were identified as barriers; mistrust of health workers, financial constraints, myth and misconceptions, lack of social support from their partners and misplacement of IUD leading to pregnancy.

The cost attached to IUD service provision and unavailability of IUDs in health facilities discourages some women from using IUD because they must pay in order to insert or remove the IUD. This barrier is worsened by the lack of social support from partners that deters women from asking for financial support from their husbands who are bread winners and do not support the use of family planning. This barrier was cited by both women using IUDs and those who were not)

"imagine nurse what I went through when my IUD got misplaced, I had only 10000(Ugandan shillings) with me, I couldn't ask anybody money, my husband didn't know about it, because I had lied to him that it's an infection, I was so... scared but if the same problem happens to others, they may end up discontinuing and decide to give birth to children. Some may be doing it secretly, lack money even to take them to the hospitals" (participant 8)

Some women believed that of some health providers were incompetent and they developed mistrust. And others cited the process of IUD insertion as uncomfortable, and painful which deters them form using it. And indeed, the latter was described as a negative experience among the users as described above

"... have ever seen someone... it seems they (healthcare provider) had inserted it badly. She was complaining that it hurt her uterus and they were almost removing it (IUD). There is also another one who got pregnant with it, yeah they say women get pregnant with it" (FGD 1) 
"... going and un dress, squat (expose private parts) for the health worker, \{she laughs\} when you have not gone to give birth" (Participant 7)

The women had myth and misconceptions about IUD and these included; misplacement of IUD during sexual intercourse abnormal fetus when the IUD is misplaced, getting cancer, fibroids due to its long use, fear of strings getting stack and fearing to have sex with their husband because it would cause injury to the cervix. These concerns were reported by both users and non-users. These resonated a lot in these quotes;

they (other people) tell us that it causes cancer when it over stays in you, it can burn you \{she laughs\} things like those, those who are not health workers... they have the perception that it can cause cancer, death and very many other things like burning lungs, uterus, things like it(IUD)can be knocked off(displaced) during sex...." (participant 4)

Some women reported the fear of getting pregnant when the IUD is misplaced and the inability to easily recognize such situations and some restrictions that come with IUD use such as good hygiene and limiting sexual partners.

"...it worries me, because they taught us that incase a man goes and gets another woman and he gets UTI not UTI, sorry STI you can also get it, and immediately you contract it you have to remove eeeee that's where my fear is..." (participant 1')

"... I heard about it with a woman when we were in the market, she told me for her she was using it .... She was married but complaining about it, saying it(IUD) does not want a second man you are supposed to have only one man (she laughs) (FGD 4)

\section{Discussion}

This study explored women's experiences, their motivations and barriers to IUD use. The positive experiences which were reported by women included; IUD is a long-term method of family planning; un affected libido, no changes in body size, reassurance from the health providers. The negative experiences included; pain on insertion; discomfort, bleeding and fear of strings. The motivators were; availability of IUD services, body image, information from the health workers and the barriers included; mistrust of health providers, financial constraints, myth and misconceptions and lack of social support.

\section{Experiences faced by WRA using IUD contraceptive}

According to Ugandan guidelines, women are supposed to be screened first for cervical cancer before IUD insertion. In this study the women appreciated knowing their cervical cancer status although they had only come for IUD insertion. This is a good strategy promoting service integration where a woman can receive more than one services in one place or even better in one procedure. WHO recommends the management and delivery of health services so that clients receive a continuum of preventive and curative services, according to their needs over time and across different levels of the health system (8). Studies have shown that integration of services increases client satisfaction, its cost effectiveness (9). This calls for more studies to integrate services about IUD.

Peer support has powerful potential to improve health behavior change in this study some women received information from their friends that made them use IUD. Studies have shown that peer support can; enhance access to health behavior information and resources, practice and apply problem-solving skills with group feedback and support, discuss health behavior challenges and barriers, sharing health behavior changes, sharing perceived health outcome improvements and benefits, feelings of belonging and being cared for, and addressing health of family and community (10). This is what exactly happened in this study. However, for mothers who experienced challenges and side effects discouraged other mothers from using IUD. This is in agreement with a study done in Ghana which found out that the willingness and ability of young women to use FP methods and services were affected often negatively, by factors operating within and across each level and some of those factors included peer influence, non-spousal support and support and lack of support from relative (11). It also indicates a need to increase on socializing ability of the women using the method with those not yet using the method to proof their good experiences so as to increase on the IUD usage. A study done on interest in and experience of self IUD removal showed 
similarly how women could freely pass on the good experience they had encountered to their peer friends (12). Intra Uterine Device (IUD) has a lot of advantages however in this study the women who used IUD liked it because it was convenient, they didn't have to keep taking the pill, their body image didn't change as compared to hormonal methods and they also acknowledged that their sexual desire or libido did not change. These are very important advantages from the perspective of women because studies have shown women usually move from one method of family planning because of change in body size and other related side effects. Studies have shown that most people switch methods mainly because of method related side effects $(13,14)$. Women will use a method if they don't experience a lot of side effects and if they are comfortable with the method.

\section{Motivations to choose IUD contraceptive}

It's important to consider the strength of women's fertility motivations when determining who has a need for family planning services. In this study women highlighted the reasons why they were using IUD. Most of them said that IUD has fewer side effects as compared to injectable family planning, others said that their body size didn't change and they had normal libido unlike when they were using hormonal methods like implants and injectable (15). Similarly studies have showed related information, that IUD does not require daily adherence and save users from adverse effects of the methods containing hormones such as injectaplan $(16,17)$. Other women highlighted its convenience where you don't have to take it every day or return to the health facility for another dose. Similarly Peipert (18) showed related information, that IUD does not require daily adherence and save users from adverse effects of the methods containing hormones such as injectaplan. This remains one of the strong incentives why women chose IUD contraceptive. The encouragements to use IUD can now depend on disseminating levels and measures about its benefits. Likewise, in this qualitative study (15) women said how they had faced no interference with their sexual feelings though some were not sure whether it is due to IUD use or not. To most of these women using IUD, these motivations were the basis for the uptake of the method. This still explains the importance of IUD over other methods.

\section{Barriers influencing the use of IUD contraceptive}

Although, most countries have made great strides in increasing access to and voluntary use of family planning including Uganda since the landmark International Conference on Population and Development in Cairo in 1994. In this study women expressed fear to use IUD and most of the issues raised were myth and misconception. The fear that IUD causes cancer, fibroids, can get stuck in the uterus discouraged women from using IUD. Studies done in some urban cities in Africa found similar myths like contraceptives can harm your womb and in another study both in Rwanda and Ethiopia mother expressed fear of IUD disappearing in the uterus during sexual intercourse and fear of procedure thus limiting them from taking up family planning especially IUD $(19)(20,21)$. According to our study fear plays a very important part in hindering IUD use. This could explain why Uganda still has a low IUD use rate and a need is required to increase its use. Several studies have been done and revealed fears of different categories which also were considered to be barriers for the uptake of IUD. These included hurting of the reproductive tract (22) and expulsion of the IUD (23). This implies that more effort is needed in training the health providers and intense counseling and teaching should be done during the teaching sessions of these mothers. This can be fruitful when even community outreaches are done because some mothers are taught at facilities but most of them do not come to health facilities. Also, private clinics/ facilities must be availed with all the necessary resources to also target those attending them and better approaches during FP sessions must be availed to dispel the myths and misconceptions. Furthermore, IUD is still believed to be second line method in failure of other methods, good use when other contraceptive methods have been failed. This explains why IUD use is still very low. Similarly a study has been done which indicate the related information were women opted to use IUD after failing with other methods (24).

Financial support remains a very important aspect in regards to access of maternal and child Health especially use of IUD. This study revealed the financial implications as being one of the leading barriers to pick up IUD. Given the insufficiencies in the public health system FP users are likely to seek treatment for side effects from private health facilities which may not be affordable to most of them. It is important that in the interest of equitable centered services, provision of free public sector FP

Page $8 / 12$ 
services should be accompanied by readily available therapies for side effects. The importance of involving men in reproductive, maternal and child health programs is increasingly recognized globally. In most maternal and child health services including family planning do not actively engage men were reported as being less involved in the female's reproductive decisions making yet they majorly depend on their husbands. This is because most of these women do not work and those who work earn little. Many studies revealed the same aspect as the barriers towards using IUD these generally included perceived knowledge about method being very low and they were concerned about the costs $(6,25)$ This calls for men involvement in the FP programs. The immediate negative financial implications may dominate this long-term benefit if there is a gap in empowerment and public sector support. Further research to understand the financial impact of FP side effects is recommended.

During family planning provision it mandatory to provide holistic information about the method. In this study women highlighted that the providers only provided the advantages and the good things about IUD and they never provided information on side effects. This made mothers change the method because of side effects (22). It is important to effectively talk about the negatives and positives of the method to avoid premature discontinuation of the method. This was also showed in the results found in the study conducted on female undergraduates at a large mid-western university in USA which indicated that women's perceived knowledge about IUD was inadequate as compared to knowledge found out (26).

\section{Conclusion}

The experiences were both positive and negative, the motivators were their drivers to use the method and barriers were reported to influence the IUD use. There is need for mothers who have used IUD and are satisfied with the method to talk to other mothers so that we can increase IUD use as a method of family planning and health care providers have role to play to demystify the myth and misconceptions the mother have.

\section{Recommendations}

There is need to involve male more in decision making of health issues including family planning. The health care providers need to continually health educate and dispel myth and misconception about family planning more especially IUD

\section{Limitations}

Since women were selected purposively, only WRA who came to the facility on days when principle researcher was conducting research had the chance to participant in the study.

\section{Abbreviations}

UDHS: Uganda Demographic and Health Survey; FGDs: Focus Group Discussions': International Federation for Gynecologist and Obstetricians; IUDs: Intrauterine Devices; MOH: Ministry of Health; WRA: Women of Reproductive age; UNFPA: United Nations Fund for Populations Activities; USAID: United State Agency for International Development; WHO: World Health Organization

\section{Declarations}

\section{Ethics approval and consent to participate}

Ethical review and approval were obtained from the Higher Degrees and Research Ethics Committee of the College of Health Sciences at Makerere University \#SHSREC REF NO: 2018-065. The administrative clearance and permissions were obtained from Nakaseke hospital administration. Written informed consent was obtained from the mothers and the midwives.

Participation was voluntary and all the interviews were conducted in private settings to ensure participant's confidentiality. 
Not applicable

\section{Availability of data and materials}

The datasets used and /or analyzed during the current study are not publicly available due to some privacy reason, but are available from the corresponding author on reasonable request.

\section{Competing interests}

The author(s) declare that they have no competing interests.

\section{Funding}

The work was supported by Grant Number D43TW010132 supported by Office of the Director, National Institutes of Health (OD), National Institute Of Dental \& Craniofacial Research (NIDCR), National Institute Of Neurological Disorders And Stroke (NINDS), National Heart, Lung, And Blood Institute (NHLBI), Fogarty International Center (FIC), National Institute On Minority Health And Health Disparities (NIMHD). Its contents are solely the responsibility of the authors and do not necessarily represent the official views of the supporting offices.

Research reported in this publication was supported by the Fogarty International Center of the National Institutes of Health under Award Number 1R25TW011213. The content is solely the responsibility of the authors and does not necessarily represent the official views of the National Institutes of Health.

\section{Authors' contributions}

NT, SNM designed the study, collected and analysed the data, drafted the paper and reviewed the paper, CO contributed to the analysis of the study and reviewed the paper. CPO contributed to the analysis, and reviewing the paper, JK contributed to the reviewed the paper. All the authors approved the final draft of the paper.

\section{Acknowledgements}

We would like to acknowledge all those who participated in the study. we are also grateful to thank the study participants, research assistants, the management and staff for Nakaseke district hospital for their great contribution and support.

\section{References}

1. Say L, Chou D, Gemmill A, Tunçalp Ö, Moller A-B, Daniels J, et al. Global causes of maternal death: a WHO systematic analysis. The Lancet Global Health. 2014;2(6):e323-e33. https://doi.org/10.1016/S2214-109X(14)70227-X

2. Dragoman M, Sheldon W, Qureshi Z, Blum J, Winikoff B, Ganatra B, et al. Overview of abortion cases with severe maternal outcomes in the WHO M ulticountry S urvey on M aternal and N ewborn $\mathrm{H}$ ealth: a descriptive analysis. BJOG: An International Journal of Obstetrics \& Gynaecology. 2014;121:25-31. https://doi.org/ 10.1111/1471-0528.12689

3. Buhling KJ, Zite NB, Lotke P, Black K. Worldwide use of intrauterine contraception: a review. Contraception. 2014;89(3):16273. https://doi.org/1016/j.contraception.2013.11.011

4. Uganda Bureau of Statistics, ICF. Uganda demographic and health survey 2016: key indicators report. UBOS, and Rockville Maryland; 2017. https://health.go.ug/sites/default/files/Demographic\%20and\%20Health\%20Survey.pdf

5. Twesigye R, Buyungo P, Kaula H, Buwembo D. Ugandan women's view of the IUD: generally favorable but many have misperceptions about health risks. Global Health: Science and Practice. 2016;4(Supplement 2):S73-S82.

https://doi.org/10.9745/GHSP-D-15-00304

6. Nalwadda G, Mirembe F, Tumwesigye NM, Byamugisha J, Faxelid E. Constraints and prospects for contraceptive service provision to young people in Uganda: providers' perspectives. BMC health services research. 2011;11(1):220.

https://doi.org/10.1186/1472-6963-11-220

Page $10 / 12$ 
7. Braun V, Clarke V. Using thematic analysis in psychology. Qualitative research in psychology. 2006;3(2):77-101. DOI: 10.1191/1478088706qp063oa

8. Berwick D, Nolan T. J. Whittington, 2008. The Triple Aim: Care. Health, and Cost Health Affairs.27(3):759-69. https://doi.org/10.1377/hlthaff.27.3.759

9. Heyeres M, McCalman J, Tsey K, Kinchin I. The complexity of health service integration: a review of reviews. Frontiers in public health. 2016;4:223. https://doi.org/10.3389/fpubh.2016.00223

10. Lee S, Schorr E, Hadidi NN, Kelley R, Treat-Jacobson D, Lindquist R. Power of Peer Support to Change Health Behavior to Reduce Risks for Heart Disease and Stroke for African American Men in a Faith-Based Community. Journal of racial and ethnic health disparities. 2018;5(5):1107-16. https://doi.org/10.1007/s40615-018-0482-1.

11. Challa S, Manu A, Morhe E, Dalton VK, Loll D, Dozier J, et al. Multiple levels of social influence on adolescent sexual and reproductive health decision-making and behaviors in Ghana. Women \& health. 2018;58(4):434-50. https://doi.org/10.1080/03630242.2017.1306607

12. Anderson N, Steinauer J, Valente T, Koblentz J, Dehlendorf C. Women's social communication about IUDs: a qualitative analysis. Perspectives on sexual and reproductive health. 2014;46(3):141-8. https://doi.org/10.1363/46e1814

13. Atnafe $\mathrm{M}$, Assefa N, Alemayehu T. Long-acting family planning method switching among revisit clients of public health facilities in Dire Dawa, Ethiopia. Contraception and reproductive medicine. 2016;1(1):18. https://doi.org/10.1186/s40834016-0028-z

14. Barden-O'Fallon J, Speizer IS, Calhoun LM, Corroon M. Women's contraceptive discontinuation and switching behavior in urban Senegal, 2010-2015. BMC women's health. 2018;18(1):35. https://doi.org/10.1186/s12905-018-0529-9

15. Higgins JA, Ryder K, Skarda G, Koepsel E, Bennett EA. The sexual acceptability of intrauterine contraception: a qualitative study of young adult women. Perspectives on sexual and reproductive health. 2015;47(3):115-

\section{2. https://doi.org/10.1363/47e4515}

16. Peipert JF, Zhao Q, Allsworth JE, Petrosky E, Madden T, Eisenberg D, et al. Continuation and satisfaction of reversible contraception. Obstetrics and gynecology. 2011;117(5):1105. doi: 10.1097/AOG.0b013e31821188ad

17. Spies EL, Askelson NM, Gelman E, Losch M. Young women's knowledge, attitudes, and behaviors related to long-acting reversible contraceptives. Women's health issues. 2010;20(6):394-9. https://doi.org/10.1016/j.whi.2010.07.005

18. Peipert JF, Madden T, Allsworth JE, Secura GM. Preventing unintended pregnancies by providing no-cost contraception. Obstetrics and gynecology. 2012;120(6):1291. https://doi.org/10.1016/j.whi.2010.07.005

19. Endriyas M, Eshete A, Mekonnen E, Misganaw T, Shiferaw M. Where we should focus? Myths and misconceptions of long acting contraceptives in Southern Nations, Nationalities and People's Region, Ethiopia: qualitative study. BMC pregnancy and childbirth. 2018;18(1):98. https://doi.org/10.1186/s12884-018-1731-3

20. Gueye A, Speizer IS, Corroon M, Okigbo CC. Belief in family planning myths at the individual and community levels and modern contraceptive use in urban Africa. International perspectives on sexual and reproductive health. 2015;41(4):191. doi:10.1363/4119115

21. Farmer DB, Berman L, Ryan G, Habumugisha L, Basinga P, Nutt C, et al. Motivations and constraints to family planning: a qualitative study in Rwanda's southern Kayonza District. Global Health: Science and Practice. 2015;3(2):242-54.

https://doi.org/10.9745/GHSP-D-14-00198

22. Dasari M, Borrero S, Akers AY, Sucato GS, Dick R, Hicks A, et al. Barriers to long-acting reversible contraceptive uptake among homeless young women. Journal of pediatric and adolescent gynecology. 2016;29(2):104-10.

https://doi.org/10.1016/j.jpag.2015.07.003

23. Reiss K, Nantayi L, Odong J, Ngo TD. Providing long-acting and permanent contraceptives through outreach in rural Uganda. London: Marie Stopes International. 2012;2(1):20-3.

https://www.researchgate.net/profile/Kate_Reiss/publication/283321487_Providing_long-

acting_and_permanent_contraceptives_through_outreach_in_rural_Uganda/links/5633491408ae242468db8674/Providinglong-acting-and-permanent-contraceptives-through-outreach-in-rural-Uganda.pdf

Page $11 / 12$ 
24. Darroch JE. Trends in contraceptive use. Contraception. 2013;87(3):259-63.

https://doi.org/10.1016/j.contraception.2012.08.029

25. Weisberg E, Bateson D, McGeechan K, Mohapatra L. A three-year comparative study of continuation rates, bleeding patterns and satisfaction in Australian women using a subdermal contraceptive implant or progestogen releasingintrauterine system. The European Journal of Contraception \& Reproductive Health Care. 2014;19(1):5-14. https://doi.org/10.3109/13625187.2013.853034

26. Vaaler ML, Kalanges LK, Fonseca VP, Castrucci BC. Urban-rural differences in attitudes and practices toward long-acting reversible contraceptives among family planning providers in Texas. Women's Health Issues. 2012 Mar 1;22(2):e157-62. https://doi.org/10.1016/j.whi.2011.11.004 